Running Head: PSYCHOSOCIAL OUTCOMES OF ADULTS WITH ASD

\title{
High-Functioning Autism Spectrum Disorder in Adulthood: A Systematic Review of Factors Related to Psychosocial Outcomes
}

David Zimmerman $^{1}$, Tamara Ownsworth ${ }^{1}$, Analise O’Donovan ${ }^{1}$, Jacqueline Roberts ${ }^{2}$, Matthew J Gullo ${ }^{3}$

${ }^{1}$ School of Applied Psychology and Griffith Health Institute, Behavioural Basis of Health, Griffith University, Australia

${ }^{2}$ School of Education and Professional Studies, Griffith University, Australia

${ }^{3}$ Centre for Youth Substance Abuse Research (CYSAR), University of Queensland

Short title: Psychosocial Outcomes of Adults with High Functioning Autism Spectrum Disorder

\section{Corresponding author:}

David Zimmerman

School of Applied Psychology

Griffith University

Mt Gravatt, 4122

Ph: +61 421152192

Fax: +61 737353399

Email: david.zimmerman@griffithuni.edu.au

Conflict of Interest and Sources of Funding: There are no conflicts of interest to declare relating to any of the authors. No specific funding was utilised in conducting this review or preparing this manuscript, which was produced in partial fulfilment of $\mathrm{PhD}$ requirements for the first author. MJG is supported by a National Health and Medical Research Council of Australia Early Career Fellowship (APP1036365).

This is the preprint version of a published journal article. Please cite as:

Zimmerman, D., Ownsworth, T., O’Donovan, A., Roberts, J., \& Gullo, M. J. (2018). High-functioning autism spectrum disorder in adulthood: A systematic review of factors related to psychosocial outcomes. Journal of Intellectual \& Developmental Disability, 43(1), 2-19. 
Running Head: PSYCHOSOCIAL OUTCOMES OF ADULTS WITH ASD

\begin{abstract}
Background: This systematic review aimed to identify the factors related to psychosocial outcomes for adults with high functioning autism spectrum disorder (HFASD). A further aim was to appraise the research methodology and provide recommendations for future research.
\end{abstract}

Method: Systematic review methodology was used to comprehensively search for peer reviewed articles, assess methodological rigor and summarise the results. Twenty-seven studies published between 1989 and December 2015 met inclusion criteria and included 1398 individuals $(M$ age $=28.54$ years $)$ with HFASD $($ IQ $\geq 70)$.

Results: Factors most consistently found to be related to poor psychological, social and adaptive outcomes included: greater symptom severity, lower childhood IQ, impaired non-verbal learning, cognitive shifting deficits, negative thinking styles, and perceptions of low social support.

Conclusions: Overall, key risk factors for poor psychosocial outcomes of adults with HFASD were identified. However, further prospective longitudinal research with large samples is needed to examine the complex, and potentially bi-directional relationships among these factors.

Key words: adults, high-functioning, autism spectrum disorder, psychosocial outcomes 
Running Head: PSYCHOSOCIAL OUTCOMES OF ADULTS WITH ASD

\section{Introduction}

Autism spectrum disorder (ASD) is a grouping of neurodevelopmental disorders characterised by deficits in social communication and language as well as a restricted range of behaviours or interests (American Psychiatric Association, 2013). A wealth of studies have investigated the aetiology and characteristics of ASD in children and adolescents (Chiang \& Wineman, 2014; Levy \& Perry, 2011). Reviews of the empirical literature to date have focused broadly on social and adaptive outcomes of individuals with high and low functioning ASD (e.g., Magiati, Tay, \& Howlin, 2014; Tobin, Drager, \& Richardson, 2014) and across different developmental phases (e.g., Chiang \& Wineman, 2014). Less is known about the psychological, social and adaptive outcomes of adults with ASD who are "high-functioning" in the sense that their intellectual functioning is in the normal range (i.e., $\geq 70$ ), commonly referred to as high functioning ASD (HFASD; see Baron-Cohen, 2000).

Due to the multidimensional nature and complex symptomatology of ASD, no single theory can comprehensively account for the characteristics and outcomes of the disorder (Silva et al., 2013). It has been proposed that diverse factors potentially account for differences in psychological, social and adaptive outcomes. These include demographic characteristics, neurocognitive functioning, severity of ASD symptoms, self-appraisals, emotion regulation and coping skills, and social support (Attwood, 2007). From this perspective, psychosocial outcomes could incorporate both mental health (e.g., depression, anxiety, stress, self-esteem, psychotic symptoms, attention deficit hyperactivity disorder, quality of life) and social and adaptive functioning (e.g., levels of independence, vocational, academic and interpersonal functioning) domains.

A leading neurocognitive developmental account of ASD implicates deficits in social cognition such as theory of mind (ToM), or the ability to evaluate the mental states of others (Baron-Cohen, Wheelwright, Hill, Raste, \& Plumb, 2001; Frith \& Frith, 
Running Head: PSYCHOSOCIAL OUTCOMES OF ADULTS WITH ASD

2003). A second major neurocognitive developmental account, weak central coherence theory, proposes that individuals with ASD have pervasive difficulties with perceiving the overall meaning or gist in a given situation, which leads to processing information in a fragmented and fine-grained way (Frith \& Happé, 1994; Rajendran \& Mitchell, 2007). Aspects of ASD symptomatology unaccounted for by ToM and weak central coherence theories have been proposed to arise from deficits in executive functioning such as problems with attentional switching, perseveration and impulse control (Hill, 2004; Kleinhans, Akshoomoff, \& Delis, 2005). Despite generally mixed empirical support concerning the profile of executive function impairments in ASD (Hill \& Bird, 2006; Pennington \& Ozonoff, 1996; Rajendran, Mitchell, \& Rickards, 2005; Turner, 1999), there is consistent evidence of difficulties with cognitive shifting (i.e., the ability to engage and disengage actions in the service of predominant goals; Ambery, Russell, Perry, Morris, \& Murphy, 2006; Hill \& Bird, 2006; Pellicano, 2007). However, the influence of neurocognitive functioning on psychosocial outcomes in adults with HFASD is unclear.

The ways in which individuals perceive themselves and their environment has long been recognised to impact on psychological and social functioning in the context of chronic health conditions (Lauwerier et al., 2010; McCracken, 2005). Research has shown that adolescents with HFASD perceive themselves as different and report lower self-esteem than typically developing peers (Vickerstaff, Heriot, Wong, Lopes, \& Dossetor, 2007; Williamson, Craig, \& Slinger, 2008). Qualitative studies indicate that some individuals perceive positive effects of being diagnosed with ASD and are motivated to seek out likeminded individuals and community support groups (Haertl, Callahan, Markovics, \& Sheppard, 2013). In contrast, others express feeling helpless, estranged, and rejected by society (Haertl et al., 2013; Smith \& Sharp, 2013; Townson et al., 2007). Individuals may also value certain skills associated with ASD, such as 
Running Head: PSYCHOSOCIAL OUTCOMES OF ADULTS WITH ASD

identifying errors quickly and understanding complex mathematics and computers (Smith \& Sharp, 2013). Such findings highlight the importance of examining the impact of self-appraisals on psychosocial outcomes for adults with HFASD.

Individuals with ASD are prone to heightened stress and comorbid psychological diagnoses (Baron, Groden, \& Groden, 2006; Samson, Huber, \& Gross, 2012). Yet, investigations of stress and coping have mainly focused on family members (Baron et al., 2006; Dabrowska \& Pisula, 2010; Pottie \& Ingram, 2008). Stress is thought to detrimentally influence health outcomes on a number of inter-related levels whereby stressful situations trigger negative appraisals of harm, activate physiological systems and elicit unhelpful coping responses (e.g., avoidance, alcohol and illicit drug use; Cohen, Kessler, \& Gordon, 1995; Lazarus \& Folkman, 1984). Long-term activation of stress response systems is associated with a heightened risk of developing a range of physical and psychiatric disorders (DeLongis, Folkman, \& Lazarus, 1988; Rosengren, Orth-Gomer, Wedel, \& Wilhelmsen, 1993).

Related to self-appraisals and coping resources, emotion regulation refers to the capacity to simultaneously attend to internal and external cues in order to respond appropriately in a given situation (Ekman, 1992). Samson and colleagues (2012) found that adults with HFASD were less likely to use reappraisal strategies when regulating emotions in a stressful situation than matched controls. Therefore, self-appraisals, coping and emotion regulation skills are important to examine as personal resources potentially related to psychosocial outcomes of HFASD in adulthood.

In addition to emotion regulation skills, social resources can buffer the detrimental effects of stressful events on well-being (Cohen, 1988). In particular, social support has been found to moderate the impact of high levels of stress on psychological well-being (Cohen, 2004). A fundamental aspect of this buffering effect is the extent to which social support is perceived as available or effective by an individual (Cohen, 
Running Head: PSYCHOSOCIAL OUTCOMES OF ADULTS WITH ASD

1988). There is considerable evidence that the perceived availability and quality of social support moderates the influence of high levels of stress on health outcomes in a range of clinical populations (Payne et al., 2012; Steptoe, 2000). However, the influence of perceived social support on psychosocial outcomes of adults with HFASD has received little attention to date.

Broader social environmental factors likely to influence psychological, social adaptive outcomes include the quality of interactions with friends, family and employers (Chiang \& Wineman, 2014; Howlin, 2000; Levy \& Perry, 2011; Tobin et al., 2014). In particular, the experience of bullying and victimisation during childhood and adolescence, most commonly in the school environment, has been proposed to contribute to poor psychosocial outcomes in adulthood (Cappadocia, Weiss, \& Pepler, 2012; Roekel, Didden, \& Scholte, 2010). In an unpublished dissertation, Merkler (2007) reported that adults with HFASD were more isolated than matched controls and that isolation from social networks and relationships was associated with psychological distress. Despite their social challenges, individuals with HFASD have been found to report a desire for intimacy and social connectedness and derive satisfaction from contributing to others' welfare (Muller, Schuler, \& Yates, 2008). A better understanding of social environmental influences on outcomes of adults with HFASD may guide support interventions.

\section{Rationale and Aims of the Systematic Review}

Previous reviews of factors related to psychosocial outcomes of ASD have typically synthesised the findings for children and adults with high and low functioning ASD (Chiang \& Wineman, 2014; Howlin \& Moss, 2012; Levy \& Perry, 2011; Magiati et al., 2014; Nordin \& Gillberg, 1998; Tobin et al., 2014; van Heijst \& Geurts, 2014). For example, Levy and Perry (2011) found that autism severity, cognitive and language skills, co-morbid psychopathology and access to interventions were consistently related 
Running Head: PSYCHOSOCIAL OUTCOMES OF ADULTS WITH ASD

to outcomes for adolescents and adults with ASD. More recently, Magiati et al. (2014) reviewed 25 longitudinal studies of cognitive, language and behavioural outcomes of adults with ASD. The key findings were that IQ typically remained stable between childhood and adulthood and that early IQ and language skills predicted functional outcomes in adulthood. Improvements were evident between childhood and adulthood for ASD symptoms, language and adaptive functioning; however, social outcomes were generally poor and the majority still met partial criteria for ASD in adulthood.

Overall, given the heterogeneity of study samples encompassing participants with high and low functioning ASD (e.g., Magiati et al., 2014; Tobin et al., 2014) and children and adults (e.g., Chiang \& Wineman, 2014), it is unclear to what extent these findings generalise to adults with HFASD. Further, greater emphasis has been placed on neurocognitive predictors than self-appraisals, coping resources and aspects of the social environment which are potentially responsive to intervention (Tobin et al., 2014). To guide future research and support interventions specific to adults with HFASD, it is important to understand both risk factors and protective factors impacting long-term psychosocial outcomes.

Accordingly, the broad aims of this systematic review were to identify studies investigating factors associated with psychosocial outcomes of adults with HFASD and synthesise the key findings. A further aim was to appraise the research methodology, identify gaps in the literature and provide future research recommendations. As mentioned previously, psychosocial outcomes broadly include mental health and social and adaptive functioning.

\section{Method}

The current paper adopted systematic review methodology in accordance with relevant guidelines outlined by the Preferred Reporting Items for Systematic Reviews and Meta-Analyses (PRISMA; Moher, Liberati, Tetzlaff, \& Altman, 2009). This review 
Running Head: PSYCHOSOCIAL OUTCOMES OF ADULTS WITH ASD

process entailed four stages: 1) searching electronic databases using key terms; 2)

reviewing abstracts with potentially relevant titles and key terms; 3) reviewing the fulltext of articles to determine eligibility (conducted by two authors); and 4) appraising the methodology of eligible studies and summarising the findings.

\section{Search Strategy}

Eligible articles were identified through systematic electronic searches of the following databases: Ovid (PsycINFO), ProQuest, PubMed, Science Direct, Scopus and Web of Science from inception to the end of October 2015. Keyword searching (i.e. searching of title, abstract, keyword and/or subject) was used for the following terms: 1) autism spectrum disorder or Asperger* or high-functioning autism or high functioning autism or HFASD; AND 2) outcome* or psychosocial or mental health or depression or anxiety or self-esteem.

Search terms were chosen based on Diagnostic and Statsitical Manual for Mental Disorders-Fourth Edition (DSM-IV; 1994), DSM-IV-TR (2000), DSM-5 (2013) and International Classification of Diseases-Tenth Revision (ICD-10; 1993) terminology for people with high-functioning autism spectrum disorder (or Asperger's Syndrome/Disorder) as relevant to the specific focus of our review.

Searches were limited to adults either via limits or through the additional search terms: AND adult*. In addition, specific autism journals (i.e., Autism Research, Journal of Autism and Developmental Disorders, Journal of Intellectual and Developmental Disability and Autism) were screened for articles published online that may not have been identified through the original database search. Finally, the reference lists of eligible studies were also manually searched.

\section{Selection Criteria}

To identify relevant studies, the following inclusion criteria were applied: peerreviewed articles published in English; quantitative studies (i.e., use of statistical 
Running Head: PSYCHOSOCIAL OUTCOMES OF ADULTS WITH ASD

analysis) that investigated factors related to psychosocial outcomes in adults with HFASD; mean age for the HFASD sample was at least 18 years and the minimum age of a participant was 16 years; participants had a formal diagnosis of ASD and/or ASD severity was measured; and participants' IQ was in the normal range (i.e., $\geq 70$ ), or intellectual disability was specified in exclusion criteria.

All abstracts of articles that met these inclusion criteria were reviewed by the primary author. Articles were excluded if they were reviews, commentaries or case studies or if they only employed qualitative methodology. Despite having an empirical basis, the findings of case studies and qualitative studies require a different approach to synthesis that was outside the scope of this review.

Following the initial screening stage, the full-text of each article was independently reviewed by two authors. Level of agreement concerning eligibility for inclusion was quantified using a point-by-point method (i.e., number of

agreements/[agreements + disagreements $]$ x $100=\%$ agreement $)$.

\section{Quality of Methodology}

The final stage of the review process involved evaluating the methodological quality of the eligible studies according to a checklist adapted from Ownsworth and McKenna (2004). Articles were scored 0 (does not meet) or 1 (meets) on the following five criteria: 1) prospective and/or retrospective design employed with at least two assessment time points (i.e., collection of data on childhood variables and follow-up of outcomes in adulthood); 2) characteristics of the sample (i.e., age, gender, IQ and ASD status) and the inclusion criteria for the study were clearly stated; 3) analysis of sample representativeness was conducted. For prospective (and retrospective) studies, participants lost at follow-up were described and the reasons for attrition were explained. For cross-sectional studies, a comparison was conducted between individuals who were eligible and participated and those who were eligible but did not participate; 
Running Head: PSYCHOSOCIAL OUTCOMES OF ADULTS WITH ASD

4) an adequate sample size, i.e. comprised of at least 10 participants per

predictor/independent variable (Cohen, 2013); and 5) a multivariate statistical approach was used to examine the relationship between the predictor/independent variables and outcomes with examination of, or control for other predictors or covariates. Higher scores (0-5) represented stronger methodological quality. The first author reviewed each study and rated the quality of methodology while the second author checked and confirmed the suitability of these ratings.

\section{Data Synthesis}

Due to significant variability in design, sample characteristics, analytic approach and outcome measures, meta-analysis was not used to synthesise the data. Instead, results were synthesized qualitatively.

\section{Results}

As shown in Figure 1, the initial search yielded a total of 843 articles, which reduced to 807 once duplicates and studies not published in English were removed. A further 726 articles were excluded on the basis of title or abstract, leaving a total of 67 articles to be screened for eligibility as full-texts by both reviewers. Additionally, a further six articles were identified through reviewing the content pages of specific autism journals and searching the reference lists of eligible articles. This process identified 27 articles eligible for review (see Figure 1). There was $82 \%$ agreement between two independent raters concerning the inclusion or exclusion of the 67 studies based on review of the full text. Initial disagreement regarding eligibility of 12 studies was resolved through discussion. Specifically, nine studies were included (Gillberg, Helles, Billstedt, \& Gillberg, 2015; Gotham, Bishop, Brunwasser, \& Lord, 2014; Gotham, Unruh, \& Lord, 2014; Hagberg, Billstedt, Nyden, \& Gillberg, 2015; Hagberg, Nyden, Cederlund, \& Gillberg, 2013; Hare, Wood, Wastell, \& Skirrow, 2014; Maddox \& White, 2015; Rinaldi, Jacquet, \& Lefebvre, 2015; Shtayermman, 2007), while three 
Running Head: PSYCHOSOCIAL OUTCOMES OF ADULTS WITH ASD

were not deemed eligible (Bejerot, Eriksson, \& Mortberg, 2014; Gray et al., 2014; Hare, Gracey, \& Wood, 2015). Two articles (Gotham, Bishop, et al., 2014; Gotham, Unruh, et al., 2014) employed the same sample, but analysed a different set of variables. A further two articles (Hagberg et al., 2015; Hagberg et al., 2013) also employed identical samples that involved analyses of different variables. The results of these four articles were summarised as two broader studies for the purpose of this review. Table 1 outlines the design, sample characteristics, correlates/predictors, psychosocial outcomes, quality of methodology ratings and significant findings of the 27 eligible studies.

Insert TABLE 1 about Here

\section{Participant and Sample Characteristics}

A total of 1398 individuals $(\mathrm{M}$ age $=28.54$ years $)$ with HFASD were involved across the 27 studies (published between 1989 and December 2015), with sample sizes of 10-291 (M sample size $=51.8)$. The cross-sectional study by Khanna, JariwalaParikh, West-Strum, and Mahabaleshwarkar (2014) had the largest sample size $(n=$ 291), representing $20.8 \%$ of the total participants in this review. Across the 26 studies that specified participants' gender there were 930 males (71.6\%) and 369 females $(28.4 \%)$.

\section{Quality of Methodology}

As shown in Table 2, the methodological quality was variable across the 27 studies (score range: 1-4). Based on the five criteria specified for this review, the two studies with the strongest methodological quality were a cross-sectional study $(n=141)$ by Byers et al. (2013) and a prospective study by Gillberg et al. (2015). The most common research design was cross-sectional (21/27 studies), whereas five studies employed a prospective design (Berger, Aerts, van Spaendonck, Cools, \& Teunisse, 2003; Farley et al., 2009; Gillberg et al., 2015; Hagberg et al., 2013; Taylor, Henninger, \& Mailick, 2015) and one study analysed data retrospectively across a time interval of 
Running Head: PSYCHOSOCIAL OUTCOMES OF ADULTS WITH ASD

11-27 years (Szatmari, Bartolucci, Bremner, Bond, \& Rich, 1989). The prospective study by Berger et al. (2003) is noteworthy as the only study to employ a uniform follow-up period of three years, whereas the length of follow-up period was variable for Hagberg et al. (2013), Farley et al. (2009), Gillberg et al. (2015) and Taylor et al. (2015), ranging from 9.4-24.4 years.

Most studies (22/27) provided a clear description of the sample characteristics, including age, gender, IQ and ASD status (see Table 2). In terms of sample representativeness, four studies described and compared the characteristics of individuals who were eligible and participated in the study versus those who were eligible but did not participate (Byers, Nichols, Voyer, \& Reilly, 2013; Farley et al., 2009; Gillberg et al., 2015; Szatmari et al., 1989). Two prospective and one retrospective study described participants lost at follow-up and reasons for attrition (Farley et al., 2009; Gillberg et al., 2015; Szatmari et al., 1989). Fourteen studies met the criteria for adequate sample size, with at least 10 participants per variable in the analyses (Bishop-Fitzpatrick, Mazefsky, Minshew, \& Eack, 2015; Byers et al., 2013; Gillberg et al., 2015; Gotham, Bishop, et al., 2014; Gotham, Unruh, et al., 2014; Hagberg et al., 2013; Hill, Berthoz, \& Frith, 2004; Hirvikoski \& Blomqvist, 2015; Howlin, 2003; Jansch \& Hare, 2014; Jantz, 2011; Khanna et al., 2014; Schmidt et al., 2015; Tani et al., 2012). Finally, eleven studies utilised multivariate statistical approaches to examine the relationship between independent variables and psychosocial outcomes whilst controlling for other variables (Bishop-Fitzpatrick et al., 2015; Byers et al., 2013; Hill et al., 2004; Khanna et al., 2014; Maddox \& White, 2015; Montgomery, Stoesz, \& McCrimmon, 2013; Renty \& Roeyers, 2006, 2007; Schmidt et al., 2015; Taylor et al., 2015; Wallace et al., 2015). 
Running Head: PSYCHOSOCIAL OUTCOMES OF ADULTS WITH ASD

As shown in Table 1, psychosocial outcomes were measured using a combination of clinician or researcher-rated instruments (e.g., the Vineland Adaptive Behavior Scales [VABS; Sparrow et al.,1984], Autism Diagnostic Interview-Revised [ADI-R; Lord, 1994] and Structured Clinical Interviews/Global Assessment of Functioning [DSM IV-TR; APA, 2000]) and various self-report questionnaires. The most common self-report measure used was the Beck Depression Inventory (BDI; Beck, Steer, \& Brown, 1996).

\section{Factors Associated with Psychosocial Outcomes}

Demographics: Age and Gender. Eight studies (Abell \& Hare, 2005; BishopFitzpatrick et al., 2015; Byers et al., 2013; Gotham, Unruh, et al., 2014; Khanna et al., 2014; Renty \& Roeyers, 2006; Taylor et al., 2015; Wallace et al., 2015) investigated the relationship between age and/or gender and psychosocial outcomes in adulthood. A cross-sectional study $(n=46)$ by Abell and Hare (2005) found that age was significantly and positively correlated with social anxiety and depression. Further, the cross-sectional study ( $n=38$ ) by Bishop-Fitzpatrick et al. (2015) noted that older age, and not years of education, was correlated with poorer social and adaptive functioning. However, crosssectional studies with larger samples sizes $(n=58$ and $n=291)$ by Renty and Roeyers (2006) and Khanna et al. (2014) found no significant associations between age and gender and quality of life (QoL). Further, cross-sectional research by Gotham, Unruh, et al. (2014) $(n=50)$ and Wallace et al. (2015) $(n=35)$ identified that age was not significantly related to mental health or social and adaptive outcomes. In a large internet based study on romantic relationships $(n=141)$, Byers et al. (2013) found that males reported significantly better dyadic and solitary sexual well-being than females. Age was not found to be related to sexual well-being. In a prospective study $(n=73)$ over 12 years, Taylor et al. (2015) reported that after controlling for age, males were more likely to be employed or in post-secondary education than females. Further, females were less 
Running Head: PSYCHOSOCIAL OUTCOMES OF ADULTS WITH ASD

likely than males to maintain employment or post-secondary education over time.

Overall, the findings for the influence of age and gender on psychosocial outcomes of adults with HFASD were mixed.

Severity of ASD Symptoms. Thirteen studies examined the relationship between severity of ASD symptoms and psychosocial outcomes (Byers et al., 2013; Gotham, Bishop, et al., 2014; Hirvikoski \& Blomqvist, 2015; Howlin, 2003; Jansch \& Hare, 2014; Jantz, 2011; Khanna et al., 2014; Maddox \& White, 2015; Renty \& Roeyers, 2007; Shtayermman, 2007; Szatmari et al., 1989; Tani et al., 2012; Taylor et al., 2015). In a small retrospective study $(n=16)$, Szatmari et al. (1989) found that early ASD symptoms ( $M$ age $=6$ years $)$ were not significantly associated with social and adaptive functioning in adulthood. Conversely, in the study with the largest sample size ( $n=$ 291), Khanna et al. (2014) reported that greater ASD symptom severity was associated with poorer mental health-related QoL. Similarly, cross-sectional research by Gotham, Bishop, et al. (2014) $(n=48)$ and Jansch and Hare (2014) $(n=30)$ found that higher levels of ASD impairments were significantly related to greater depressive and anxiety symptoms. Consistent with these findings, Hirvikoski and Blomqvist (2015) reported in their cross-sectional study $(n=25)$ that greater ASD symptoms were associated with higher perceived stress. Further, Maddox and White (2015) reported in their crosssectional study that greater ASD related social impairments were significantly associated with a co-morbid diagnosis of social anxiety disorder $(n=28)$. In a comparison of adults with Asperger's syndrome (i.e., no early language delays) and those with high functioning autism with early language delays, Howlin (2003) generally found no significant differences in psychosocial outcomes. However, adults with Asperger's syndrome $(n=42)$ achieved a higher level of education than those with high functioning autism with early language delays $(n=34)$. On the contrary, Taylor et al. (2015) found in their prospective study $(n=73)$ that ASD characteristics did not 
Running Head: PSYCHOSOCIAL OUTCOMES OF ADULTS WITH ASD

significantly predict participation in post-secondary vocational and/or educational activities.

In a study assessing self-reported psychosocial outcomes, Jantz (2011) identified that despite access to social interaction, information and advice, adults with HFASD ( $n$ =35) attending community social support groups with greater ASD symptoms reported increased loneliness. Similarly, in their large cross-sectional study $(n=141)$, Byers et al. (2013) found that greater ASD symptoms were related to increased sexual anxiety and lower self-esteem. Additionally, cross-sectional research $(n=99)$ by Tani et al. (2012) found that a higher level of circumscribed interests was associated with increased anxiety. As with many correlational findings, the direction of this association is unclear because higher levels of anxiety could also contribute to people developing more specific or restricted interests in activities.

Focusing on males with HFASD $(n=21)$ in a marital relationship, Renty and Roeyers (2007) reported that severity of ASD symptoms was negatively associated with spousal marital satisfaction, but not with the participants' own relationship satisfaction. Finally, Shtayermman (2007) reported a significant negative correlation between severity of ASD symptoms and level of suicidal ideation. Unexpectedly, this finding suggested that people with more severe ASD symptoms experienced lower levels of suicidal ideation. However, caution is needed when interpreting this finding given the small sample size $(n=10)$.

Measures of Neurocognitive Functioning. Eleven studies examined the relationship between measures of neurocognitive functioning and psychosocial outcomes (Berger et al., 2003; Farley et al., 2009; Gillberg et al., 2015; Gotham, Unruh, et al., 2014; Hagberg et al., 2015; Hagberg et al., 2013; Jansch \& Hare, 2014; Montgomery et al., 2013; Rinaldi et al., 2015; South et al., 2015; Szatmari et al., 1989; Wallace et al., 2015). In a prospective study $(n=41)$ with a mean follow-up of 24 years, 
Running Head: PSYCHOSOCIAL OUTCOMES OF ADULTS WITH ASD

Farley et al. (2009) found that after controlling for age at assessment, childhood full scale IQ (FSIQ) significantly predicted social and adaptive functioning in adulthood, explaining $23 \%$ of the variance. Current verbal IQ and non-verbal IQ accounted for significant additional variance (14-27\%) in social and adaptive outcomes. Therefore, adults demonstrating greater gains in IQ between childhood and adulthood experienced significantly better social and adaptive outcomes in adulthood.

Consistent with these findings, in a prospective study $(n=69)$ with a mean follow-up of approximately 10 years, Hagberg et al. (2013) reported that adults with persisting non-verbal learning problems from childhood had poorer global outcomes in adulthood than those with improved non-verbal functioning. Additionally, they found that adults with "lifelong non-verbal disability" had poorer social adaptive behaviour than those with no history of non-verbal disability. In the same sample, Hagberg et al. (2015) found that poorer childhood non-verbal IQ was associated with greater ADHD symptoms in adulthood. Similarly, Gillberg et al. (2015) $(n=50)$ reported that males with lower current FSIQ and non-verbal IQ demonstrated greater ADHD symptoms.

Further, Szatmari et al. (1989) found that current FSIQ and cognitive shifting skills (i.e., Wisconsin Card Sort Test; Grant \& Berry, 1981) were significantly and positively correlated with adaptive behaviour in adulthood. There were no significant associations between adaptive behaviour and tests of motor coordination, facial recognition and receptive language. Consistent with these findings, the prospective study $(n=30)$ by Berger et al. (2003) found that poor cognitive shifting skills in childhood was predictive of lower social competence in adulthood.

However, cross-sectional research $(n=50)$ by Gotham, Unruh, et al. (2014) reported no significant association between verbal IQ and depressive symptoms. Similarly, in their cross-sectional study $(n=35)$, Wallace et al. (2015) found that FSIQ was not significantly related to adaptive functioning, anxiety or depression. Instead, they found 
Running Head: PSYCHOSOCIAL OUTCOMES OF ADULTS WITH ASD

that poorer executive functioning (i.e., metacognition and behaviour regulation) was related to worse psychosocial outcomes. Specifically, after controlling for age and FSIQ, poorer planning (metacognition subscale) was significantly related to worse adaptive functioning $\left(s r^{2}=.29\right)$ and depression $\left(s r^{2}=.17\right)$, while deficits in shifting (i.e., behaviour regulation subscale) was related to greater anxiety $\left(s r^{2}=.38\right)$. In line with these results, a cross sectional study $(n=24)$ by South et al. (2015) reported that poorer memory (i.e., pattern separation memory) was associated with more negative emotionality.

In a small cross sectional study $(n=17)$, Rinaldi et al. (2015) found that interference control or inhibition, an executive function domain, distinguished between adults with ASD with a co-morbid diagnosis of schizophrenia and those with ASD with no co-morbid diagnosis. Although there was no significant difference between the groups on verbal and non-verbal fluency, individuals without co-occurring psychotic symptoms performed significantly better on a measure of interference control (i.e., Stroop colour naming task). However, in another cross sectional study ( $n=30)$, Jansch and Hare (2014) reported no significant associations among data gathering bias (i.e., the tendency to jump to conclusions), mentalisation and paranoid thoughts.

In the only study $(n=25)$ to examine the relationship between social cognition and psychosocial outcomes, Montgomery et al. (2013) reported a significant positive association between self-reported trait emotional intelligence and interpersonal relations. Further, individuals with greater emotional intelligence and ToM had lower social stress. There were no significant associations between FSIQ, executive functioning and interpersonal relations and social stress.

Overall, despite the diversity of neuro-cognitive factors investigated, the findings most consistently indicated significant associations between lower IQ 
Running Head: PSYCHOSOCIAL OUTCOMES OF ADULTS WITH ASD

(especially non-verbal functioning) and executive functions (i.e., cognitive shifting skills, planning and inhibition) and poorer psychosocial outcomes.

Appraisals and Coping Skills. Six studies examined the relationship between self-appraisals and coping skills and psychosocial outcomes (Abell \& Hare, 2005; Gotham, Bishop, et al., 2014; Hare et al., 2014; Hill et al., 2004; Khanna et al., 2014; Renty \& Roeyers, 2006). In a large cross-sectional study ( $n=291)$, Khanna et al. (2014) reported that maladaptive coping strategies (i.e., behavioural disengagement, denial, self-blame, self-distraction, substance abuse and venting) were significantly related to poorer physical and mental health-related QoL in adulthood. In a small cross-sectional study ( $n=21)$, Renty and Roeyers (2007) explored different coping styles employed by males with HFASD using the Ways of Coping Questionnaire (WCQ; Lazarus \& Folkman, 1984). They found no significant associations between approach coping strategies (e.g., confronting or seeking social support) and avoidance coping strategies (e.g., distancing or escape avoidance) and marital satisfaction.

Cross-sectional research by Hill et al. (2004) found that adults with HFASD ( $n=$ 27) reported greater difficulty identifying and describing their feelings (i.e., emotion processing) and were more depressed than matched controls; however, emotion processing was not significantly related to depression. In contrast, Gotham, Bishop, et al. (2014) found that rumination was significantly and positively associated with depressive symptoms, and moderated the relationship between ASD symptoms and depression. In further cross-sectional research $(n=46)$, Abell and Hare (2005) reported that greater delusional beliefs and self-consciousness were significantly related to higher levels of anxiety. Similarly, in a small cross sectional study $(n=20)$, Hare et al. (2014) found that negative thinking styles (i.e., greater self-focus and worrying) and longer periods of rumination were positively associated with anxiety symptoms. 
Running Head: PSYCHOSOCIAL OUTCOMES OF ADULTS WITH ASD

Social and Environmental Factors. Six studies investigated social and environmental factors associated with psychosocial outcomes (Gotham, Bishop, et al., 2014; Khanna et al., 2014; Renty \& Roeyers, 2006; Schmidt et al., 2015; Tani et al., 2012; Taylor et al., 2015). In the only prospective study to examine the impact of the familial context on psychosocial outcomes, Taylor et al. (2015) found that adults with $\operatorname{HFASD}(n=73)$ who had fathers with higher educational attainment were more likely to obtain and maintain education or employment activities.

Cross-sectional research $(n=58)$ by Renty and Roeyers (2006) identified that perceived informal support was more closely related to QoL than actual received support. Further, levels of perceived and received social support were stronger predictors of QoL than disability characteristics (i.e., severity of ASD symptoms and FSIQ). In a separate study, Renty and Roeyers (2007) identified that perceived informal support was related to better psychological functioning and marital adaptation for men with HFASD $(n=21)$. Similarly, in a large cross-sectional study $(n=291)$, Khanna et al. (2014) reported that greater perceptions of availability and adequacy of social support from friends were related to better physical and mental health-related QoL. Further, cross-sectional research $(n=50)$ by Gotham, Bishop, et al. (2014) reported that lower levels of perceived social support, social motivation and social participation were related to increased depression. In terms of social inclusion, Schmidt et al. (2015) found that participation in society (i.e., taking part in family, social and community activities) was significantly related to overall life satisfaction for adults with HFASD $(n=43)$.

Finally, the long-term psychosocial impact of bullying was investigated in a large cross-sectional study $(n=99)$ by Tani et al. (2012), which identified that bullying during the school years was associated with greater mood swings in adulthood. Overall, low levels of perceived social support were consistently found to be related to poorer psychosocial outcomes. 
Running Head: PSYCHOSOCIAL OUTCOMES OF ADULTS WITH ASD

\section{Discussion}

This systematic review sought to identify factors related to psychosocial outcomes for adults with HFASD. A review of the 27 selected studies indicated that demographic characteristics (i.e., age and gender), ASD symptom severity and indices of neurocognitive functioning were the most frequently investigated factors. Relatively few studies examined self-appraisals, coping strategies and social and environmental factors. Overall, the methodological quality of the studies reviewed was low (i.e., 19/27 received a rating of $<3 / 5$ ) with common limitations including the use of cross-sectional designs, small and non-representative samples, and reliance on univariate analyses that did not control for other relevant predictors or covariates. There was also considerable variability in the design, sampling characteristics, outcome measures and analytic approach of studies included.

Despite these methodological issues, a consistent finding was that severity of ASD symptoms was significantly related to diverse psychosocial outcomes, including: depression, QoL, loneliness, anxiety, stress, sexual well-being, self-esteem, martial satisfaction and suicidal ideation (Byers et al., 2013; Gotham, Bishop, et al., 2014; Hirvikoski \& Blomqvist, 2015; Howlin, 2003; Jansch \& Hare, 2014; Jantz, 2011; Khanna et al., 2014; Renty \& Roeyers, 2007; Shtayermman, 2007; Tani et al., 2012). An exception to this finding was that ASD symptoms during childhood were not related to social and adaptive functioning in adulthood (Szatmari et al., 1989). However, the small sample size $(n=13)$ and retrospective design limits the ability to draw conclusions from this study. Further, a prospective study by Taylor et al. (2015) identified that ASD characteristics were not related to post-secondary vocational or educational outcomes. Nevertheless, the present findings regarding ASD symptom severity largely concur with those of previous reviews on children and adults with high and low functioning ASD (Chiang \& Wineman, 2014; Levy \& Perry, 2011), thus 
Running Head: PSYCHOSOCIAL OUTCOMES OF ADULTS WITH ASD

highlighting that more severe ASD symptomatology represents a risk factor for poor psychosocial outcomes of adults with HFASD.

The findings regarding the influence of age and gender on psychosocial outcomes were largely mixed. In particular, Abell and Hare (2005) reported a robust positive association between age and levels of anxiety and depression. Additionally, Bishop-Fitzpatrick et al. (2015) found that older age was significantly associated with poorer social and adaptive functioning. Conversely, this association was not significant in studies by Gotham, Unruh, et al. (2014) and Wallace et al. (2015) which adopted similar methodology. Controlling for the effects of age, the prospective study by Taylor et al. (2015) reported that males were more likely to be employed or in post-secondary education than females, and that females were less likely than males to maintain employment or post-secondary education over time. Further, Renty and Roeyers (2006) and Khanna et al. (2014) found that age and gender were not related to QoL for adults with HFASD. These results contrast with the review by Chiang and Wineman (2014), who found that increasing age was related to poorer QoL in a combined group of children with high and low functioning ASD. A potential explanation for these inconsistent findings relates to different approaches to measuring QoL and adaptive functioning in the studies selected for review. For example, in the adult HFASD literature, QoL was typically assessed using self-report measures, whereas parental or caregiver ratings were more commonly used for children with ASD. It is likely that perceptions and expectations related to QoL differ for adults with HFASD as compared to parents or caregivers asked to rate a child with high or low functioning ASD.

A further main finding of this review is that neurocognitive functioning was related to various psychosocial outcomes (Berger et al., 2003; Farley et al., 2009; Gillberg et al., 2015; Hagberg et al., 2015; Hagberg et al., 2013; Montgomery et al., 2013; Rinaldi et al., 2015; South et al., 2015; Szatmari et al., 1989; Wallace et al., 
Running Head: PSYCHOSOCIAL OUTCOMES OF ADULTS WITH ASD

2015). It is noteworthy that five of the 11 studies that supported this relationship employed a prospective and/or retrospective design, thus identifying that stronger early cognitive skills (i.e., FSIQ, non-verbal learning and cognitive shifting) were associated with better social and adaptive functioning in adulthood (Berger et al., 2003; Farley et al., 2009; Gillberg et al., 2015; Hagberg et al., 2015; Hagberg et al., 2013; Szatmari et al., 1989). This mirrors the results of previous reviews of adults with high or low functioning ASD (Howlin, 2000; Levy \& Perry, 2011; Magiati et al., 2014), which is perhaps not surprising given the overlap in studies selected. However, the present review additionally highlights the early prognostic significance of deficits in executive functions, notably cognitive shifting for individuals with an IQ of $>70$ (Berger et al., 2003; Szatmari et al., 1989). In line with these findings, a cross sectional study by Wallace et al. (2015) found that deficits in cognitive shifting was related to greater anxiety. Cognitive shifting, also referred to as set-shifting or task switching, supports the ability to manage goals and self-regulate behaviour and has consistently been shown to be impaired for individuals with HFASD (Ambery et al., 2006; Hill \& Bird, 2006; Lopez, Lincoln, Ozonoff, \& Lai, 2005; Pellicano, 2007).

This review also identified other executive function domains associated with psychosocial outcomes. Specifically, difficulties with interference control (i.e., inhibition), were associated with a co-morbid diagnosis of schizophrenia (Rinaldi et al., 2015). Evidence in the literature suggests an overlap in features between ASD and schizophrenia at the biological (see Burbach \& van der Zwaag, 2009 for a review), psychological and psychosocial level (Bölte, Rudolf, \& Poustka, 2002; Eack, Bahorik, et al., 2013). In particular, difficulties in some executive processes, such as inhibition and interference control, may act as vulnerability markers for the development of psychotic symptoms (Barneveld, de Sonneville, van Rijn, van Engeland, \& Swaab, 2013). 
Running Head: PSYCHOSOCIAL OUTCOMES OF ADULTS WITH ASD

A further noteworthy finding of the present review was the relationship between poorer neuro-cognitive functioning and greater risk of ADHD symptoms in adulthood (Gillberg et al., 2015; Hagberg et al., 2015). The DSM-5 (American Psychiatric Association, 2013) recognises that comorbidity of ASD and ADHD is common, and it is estimated that $30-50 \%$ of individuals with ASD manifest ADHD symptoms (Reiersen \& Todd, 2008). There is evidence that the profile of executive function deficits for those with ASD and ADHD differs in children and adolescents (Happé, Booth, Charlton, \& Hughes, 2006). Overall, the nature of executive function deficits experienced by adults with HFASD and relationship to psychosocial outcomes remains an important area for future research.

Social cognition is often conceptualised as a component of executive function (i.e., hot executive functions; Chan, Shum, Toulopoulou, \& Chen, 2008; McDonald, 2013). A novel finding that emerged in a small cross-sectional study $(n=25)$ by Montgomery et al. (2013) is that poorer ToM and lower trait emotional intelligence were associated with higher levels of social stress. Interestingly, trait emotional intelligence was more closely related to quality of interpersonal relations than FSIQ, ToM and executive functioning. Unlike these neuro-cognitive indices, emotional intelligence, social stress and interpersonal relations were assessed using self-report measures. Hence, method variance may have contributed to the significant associations between these constructs. Although discussed in the context of social cognition in this review, emotional intelligence may also reflect coping resource (i.e., the ability to perceive, be guided by and manage one's emotions and those of others; Mayer, Salovey, Caruso, \& Sitarenios, 2001). Difficulties with social functioning have long been attributed to socio-cognitive and emotional deficits such as poor joint attention and diminished emotional expressiveness (Baron-Cohen, 1995; Baron-Cohen et al., 2001; Castelli, Frith, Happé, \& Frith, 2002; Frith \& Frith, 2003). The early influence of social 
Running Head: PSYCHOSOCIAL OUTCOMES OF ADULTS WITH ASD

cognition deficits related to emotional intelligence and ToM on the development of social competency in adults remains an important area for future research.

In relation to self-appraisal and coping variables, there was evidence from several studies that delusional beliefs, perseverative thinking, and maladaptive coping are related to psychosocial outcomes of adults with HFASD (Abell \& Hare, 2005; Gotham, Bishop, et al., 2014; Hare et al., 2015; Khanna et al., 2014). Abell and Hare (2005) identified that delusional beliefs were positively related to anxiety. Consequently, they proposed a cognitive model of the development and maintenance of paranoid and grandiose thinking styles. Similarly, perseverative thinking style was related to increased depression and also moderated the relationship between severity of ASD symptoms and depression (Gotham, Bishop, et al. (2014). Hare et al. (2014) found that thinking styles characterised by worrying and rumination were associated with anxiety. Further, in their large cross-sectional study, Khanna et al. (2014) reported that maladaptive coping strategies were related to poorer physical and mental health domains of QoL. Due to the correlational nature of these findings, it is not possible to infer the direction of relationships. Specifically, although negative thinking styles and unhelpful coping strategies may contribute to poor psychosocial outcomes, it is also plausible that emotional distress and adverse social experiences contribute to, and maintain maladaptive appraisals and coping responses. Prospective studies investigating these potentially bi-directional or reciprocal effects over time could greatly aid intervention efforts for this population. Further, research investigating the existence of cross-domain interactions among risk factors (e.g., the effects of stress and depression on executive functioning) would advance the field.

A further consistent finding of this review was the association between higher levels of perceived social support and better psychosocial outcomes (Gotham, Bishop, et al., 2014; Khanna et al., 2014; Renty \& Roeyers, 2006). These studies indicated that 
Running Head: PSYCHOSOCIAL OUTCOMES OF ADULTS WITH ASD

subjective appraisal of support (i.e., perceived quality or availability) was more closely related to psychosocial outcomes than actual received support. This finding differs from the results of the review by Levy and Perry (2011) which indicated that access to intervention programs was associated with more positive outcomes for adolescents and adults with ASD. Aside from sampling differences, a key difference is that Levy and Perry (2011) focused on functional outcomes (e.g., cognitive function, language, academic performance and social outcomes), rather than indices of subjective wellbeing (e.g., QoL and depression) as measured by the studies included in the present review (Gotham, Bishop, et al., 2014; Khanna et al., 2014; Renty \& Roeyers, 2006). As noted previously, it is possible that perceptions of social support and levels of subjective well-being have reciprocal or mutually enhancing effects. There is considerable evidence in the general clinical literature that perceived social support moderates the impact of high levels of stress on health outcomes in a range of clinical populations (Payne et al., 2012; Steptoe, 2000). However, the stress buffering effects of perceived social support on psychosocial outcomes of adults with HFASD has received little attention to date and represents an important direction for future research.

Finally, only one study by Tani et al. (2012) examined the relationship between bullying and psychosocial outcomes. Based on retrospective reports, bullying during the school years was found to be associated with mood swings in adulthood. This finding is consistent with other ASD literature which cites that the experience of being bullied, victimised or socially isolated, especially during the school years, may contribute to poor psychosocial functioning in adulthood (Cappadocia et al., 2012; Roekel et al., 2010). Interestingly, Hofvander et al. (2009) found that females with HFASD were more likely to be bullied during schooling than males. The factors that contribute to the experience of bullying (e.g., gender, ASD symptom severity, emotional intelligence, aspects of the education system) and potential mediators and/or moderators (e.g., 
Running Head: PSYCHOSOCIAL OUTCOMES OF ADULTS WITH ASD

appraisals, coping and social support) in the relationship between bullying and psychosocial outcomes in adulthood represents an important area for future research.

\section{Methodological Considerations}

The aim of the present review was to identify factors related to psychosocial outcomes of adults with HFASD. For this reason, only group studies that reported statistical analyses were included. It is important to recognise the valuable and often more in-depth accounts provided by case studies and qualitative studies, even though the aim of such studies is not to broadly generalise findings to the ASD population (Giarelli \& Fisher, 2013; Haertl et al., 2013; Muller et al., 2008; Smith \& Sharp, 2013; Townson et al., 2007). Rather, these studies may provide insight into the lived experience of a health condition within a particular social and cultural context.

In terms of the review methodology, the initial article search and screening (stages 1 and 2) and the assessment of methodological quality was not replicated by an independent researcher. However, the first and second authors independently screened full-text articles for inclusion during stage three and worked collaboratively to assess the quality of methodology of selected studies. The use of independent raters to examine methodological quality and obtain mutual agreement would increase the rigour of future reviews.

In order to achieve extensive coverage of the literature, comprehensive databases (i.e., Ovid (PsycINFO), ProQuest, PubMed, Science Direct, Scopus and Web of Science) were used to identify relevant studies. Further, specific autism journals (i.e., Autism Research, Journal of Autism and Developmental Disorders, Journal of Intellectual and Developmental Disability and Autism) and reference lists of eligible studies were manually screened for articles published online that may not have been identified through the original database search. The search terms that were selected for the present review were based on DSM-IV (1994), DSM-IV-TR (2000), DSM-5 (2013) 
Running Head: PSYCHOSOCIAL OUTCOMES OF ADULTS WITH ASD

and ICD-10 (1993) terminology to identify people with high-functioning autism spectrum disorder (Asperger's Syndrome/Disorder) as relevant to the specific focus of our review. However, it is acknowledged that a different set of search terms, including broader terms such as 'autism' and 'functioning', or indeed a search of other databases, may have yielded additional papers.

Finally, it is important to recognise that the findings of this review are based on a heterogeneous set of studies with varying methodological quality. In particular, there was wide variation with respect to study design and sample characteristics, variables examined and measurement of psychosocial outcomes. This made the process of appraising methodological quality challenging. Thus, an alternative set of criteria may have yielded different ratings of methodological quality.

\section{Conclusions and Future Directions}

The findings of this systematic review on the early prognostic significance of ASD symptom severity and neurocognitive functioning (i.e., IQ and non-verbal abilities) were largely consistent with previous reviews of the broader ASD empirical literature. The present review additionally identified that cognitive shifting deficits are an early risk factor for poor psychosocial outcomes of adults with HFASD. However, further prospective research examining the relationship between deficits in executive function and social cognition and psychosocial outcomes for adults with HFASD is warranted. Such research may guide the focus of remedial and/or compensatory strategy training programmes (see Eack, Greenwald, et al., 2013; Hare et al., 2015; Magiati, Tay, \& Howlin, 2012; Schmidt et al., 2015).

Although there were fewer studies focusing on self-appraisals and coping, there was evidence that individuals with negative thinking styles and maladaptive coping strategies experience poorer psychosocial outcomes, albeit mainly from cross-sectional research with correlational data. Due to the potentially bi-directional relationships 
Running Head: PSYCHOSOCIAL OUTCOMES OF ADULTS WITH ASD

among these factors, prospective studies are needed to better understand the development and maintenance of psychological and social difficulties over time. In terms of social and environmental factors, there was consistent support for the association between higher levels of perceived social support and better psychosocial outcomes. However, it is presently unknown whether perceived social support functions as a stress buffer between risk factors and psychosocial outcomes. More generally, examining the moderating and/or mediating role of psychological resources (e.g., appraisals, coping and social support) on the relationship between key risk factors (e.g., severity of ASD symptoms, neuro-cognitive deficits) and psychosocial outcomes would advance the field. As highlighted by qualitative research, the experience of being diagnosed with ASD, meeting likeminded people and recognising personal talents can have a positive effect on self-concept (Haertl et al., 2013; Smith \& Sharp, 2013). Therefore, it is also important to examine positive self-concept domains that may buffer the stressors associated with ASD.

In future research it is recommended that prospective designs with large and representative samples be employed to improve the generalisability of findings to the broader adult HFASD population. Greater use of multivariate analyses that control for potential covariates would increase confidence in the findings. Greater consistency in research methodology across studies (including measurement of psychosocial outcomes) would also support quantitative synthesis of findings through meta-analysis. 
Running Head: PSYCHOSOCIAL OUTCOMES OF ADULTS WITH ASD

\section{References}

Abell, F., \& Hare, D. J. (2005). An experimental investigation of the phenomenology of delusional beliefs in people with Asperger syndrome. Autism : the international journal of research and practice, 9(5), 515-531. doi:10.1177/1362361305057857

Ambery, F. Z., Russell, A. J., Perry, K., Morris, R., \& Murphy, D. G. (2006).

Neuropsychological functioning in adults with Asperger syndrome. Autism, 10(6), 551-564. doi:10.1177/1362361306068507

American Psychiatric Association. (1994). Diagnostic and statistical manual of mental disorders (4th ed.). Washington, DC: Author.

American Psychiatric Association. (2000). Diagnostic and Statistical Manual of Mental Disorders-Text Revision (4th ed.). Washington, DC: Author.

American Psychiatric Association. (2013). DSM 5: American Psychiatric Association.

Attwood, T. (2007). The complete guide to asperger's syndrome. London: Jessica Kingsley Publishers.

Barneveld, P. S., de Sonneville, L., van Rijn, S., van Engeland, H., \& Swaab, H. (2013). Impaired response inhibition in autism spectrum disorders, a marker of vulnerability to schizophrenia spectrum disorders? Journal of the International Neuropsychological Society, 19(06), 646-655.

Baron-Cohen, S. (1995). Mindblindness: An essay on autism and theory of mind. Cambridge, MA: MIT Press.

Baron-Cohen, S. (2000). Is Asperger syndrome/high-functioning autism necessarily a disability? Development and Psychopathology, 12(03), 489-500.

Baron-Cohen, S., Wheelwright, S., Hill, J., Raste, Y., \& Plumb, I. (2001). The "Reading the Mind in the Eyes" Test revised version: A study with normal adults, and adults with Asperger syndrome or high-functioning autism. Journal of Child Psychology and Psychiatry, 42(2), 241-251. doi:10.1111/1469-7610.00715

Baron, M. G., Groden, G., \& Groden, J. (2006). Assessment and coping strategies. In M. G. Baron, G. Groden, J. Groden, \& L. P. Lipsitt (Eds.), Stress and coping in autism (pp. 15-41). New York: Oxford University.

Beck, A. T., Steer, R. A., \& Brown, G. K. (1996). Beck depression inventory-II (BDI-II) (Second ed.). San Antonio, TX: The Psychological Corporation. 
Running Head: PSYCHOSOCIAL OUTCOMES OF ADULTS WITH ASD

Bejerot, S., Eriksson, J. M., \& Mortberg, E. (2014). Social anxiety in adult autism spectrum disorder. Psychiatry Research, 220(1-2), 705-707.

Berger, H. J. C., Aerts, F., van Spaendonck, K. P. M., Cools, A. R., \& Teunisse, J. P. (2003). Central coherence and cognitive shifting in relation to social improvement in high-functioning young adults with autism. Journal of Clinical and Experimental Neuropsychology, 25(4), 502-511. doi:10.1076/jcen.25.4.502.13870

Bishop-Fitzpatrick, L., Mazefsky, C. A., Minshew, N. J., \& Eack, S. M. (2015). The relationship between stress and social functioning in adults with autism spectrum disorder and without intellectual disability. Autism Research, 8(2), 164-173.

Bölte, S., Rudolf, L., \& Poustka, F. (2002). The cognitive structure of higher functioning autism and schizophrenia: a comparative study. Comprehensive Psychiatry, 43(4), 325-330.

Burbach, J. P. H., \& van der Zwaag, B. (2009). Contact in the genetics of autism and schizophrenia. Trends in Neurosciences, 32(2), 69-72.

Byers, E., Nichols, S., Voyer, S. D., \& Reilly, G. (2013). Sexual well-being of a community sample of high-functioning adults on the Autism spectrum who have been in a romantic relationship. Autism, 17(4), 418-433. doi:http://dx.doi.org/10.1177/1362361311431950

Cappadocia, M. C., Weiss, J. A., \& Pepler, D. (2012). Bullying experiences among children and youth with autism spectrum disorders. Journal of Autism and Developmental Disorders, 42(2), 266-277. doi:10.1007/s10803-011-1241-X

Castelli, F., Frith, C., Happé, F., \& Frith, U. (2002). Autsim, Asperger syndrome and brain mechanisms Brain, 125, 1839-1849. doi:10.1093/brain/awf189

Chan, R. C., Shum, D., Toulopoulou, T., \& Chen, E. (2008). Assessment of executive functions: Review of instruments and identification of critical issues. Archives of Clinical Neuropsychology, 23(2), 201-216.

Chiang, H. M., \& Wineman, I. (2014). Factors associated with quality of life in individuals with autism spectrum disorders: A review of literature. Research in Autism Spectrum Disorders, 8(8), 974-986. doi:10.1016/j.rasd.2014.05.003

Cohen, S. (1988). Psychosocial models of the role of social support in the etiology of physical disease. Health Psychology, 7(3), 269-297. doi:10.1037/02786133.7.3.269 
Running Head: PSYCHOSOCIAL OUTCOMES OF ADULTS WITH ASD

Cohen, S. (2004). Social relationships and health. American Psychologist, 59(8), 676684. doi:10.1037/0003-066X.59.8.676

Cohen, S., Kessler, R. C., \& Gordon, L. U. (1995). Strategies for measuring stress in psychiatric and physical disorders. In S. Cohen, R. C. Kessler, \& L. U. Gordon (Eds.), Measuring stress (pp. 3-28). New York: Oxford University Press.

Dabrowska, A., \& Pisula, E. (2010). Parenting stress and coping styles in mothers and fathers of pre-school children with autism and Down syndrome. Journal of Intellectual Disability Research, 54(3), 266-280. doi:10.1111/j.13652788.2010.01258.x

DeLongis, A., Folkman, S., \& Lazarus, R. S. (1988). The impact of daily stress on health and mood: Psychological and social resources as mediators. Journal of Personality and Social Psychology, 54(3), 486-495. doi:10.1037/00223514.54.3.486

Eack, S. M., Bahorik, A. L., McKnight, S. A., Hogarty, S. S., Greenwald, D. P., Newhill, C. E., . . Minshew, N. J. (2013). Commonalities in social and nonsocial cognitive impairments in adults with autism spectrum disorder and schizophrenia. Schizophrenia Research, 148(1), 24-28.

Eack, S. M., Greenwald, D. P., Hogarty, S. S., Bahorik, A. L., Litschge, M. Y., Mazefsky, C. A., \& Minshew, N. J. (2013). Cognitive Enhancement Therapy for Adults with Autism Spectrum Disorder: Results of an 18-month Feasibility Study. Journal of Autism and Developmental Disorders, 43(12), 2866-2877. doi:10.1007/s10803-013-1834-7

Ekman, P. (1992). An argument for basic emotions. Cognition and Emotion, 6(3-4), 169-200. doi:10.1080/02699939208411068

Farley, M. A., McMahon, W. M., Fombonne, E., Jenson, W. R., Miller, J., Gardner, M., ... Coon, H. (2009). Twenty-year outcome for individuals with autism and average or near-average cognitive abilities. Autism research : official journal of the International Society for Autism Research, 2(2), 109-118. doi:10.1002/aur.69

Frith, U., \& Frith, C. (2003). Development and neurophsyiology of mentalising. Philosophical Transactions of The Royal Society, 358(1431), 459-473. doi:10.1098/rstb.2002.1218

Frith, U., \& Happé, F. (1994). Autism: Beyond theory of mind. Cognition, 50(1-3), 115132. doi:10.1016/0010-0277(94)90024-8 
Running Head: PSYCHOSOCIAL OUTCOMES OF ADULTS WITH ASD

Giarelli, E., \& Fisher, K. (2013). Transition to community by adolescents with Asperger syndrome: Staying afloat in a sea change. Disability and Health Journal, 6(3), 227-235. doi:10.1016/j.dhjo.2013.01.010

Gillberg, C., Helles, A., Billstedt, E., \& Gillberg, C. (2015). Boys with Asperger Syndrome Grow Up: Psychiatric and Neurodevelopmental Disorders 20 Years After Initial Diagnosis. J Autism Dev Disord. doi:10.1007/s10803-015-2544-0

Gotham, K., Bishop, S. L., Brunwasser, S., \& Lord, C. (2014). Rumination and perceived impairment associated with depressive symptoms in a verbal adolescent-adult ASD sample. Autism Research, 7(3), 381-391. doi:10.1002/aur.1377

Gotham, K., Unruh, K., \& Lord, C. (2014). Depression and its measurement in verbal adolescents and adults with autism spectrum disorder. Autism, 1362361314536625.

Grant, D. A., \& Berry, E. A. (1981). Wisconsin Card Sorting Test. Odessa, FL: Psychological Assessment Resources.

Gray, K. M., Keating, C. M., Taffe, J. R., Brereton, A. V., Einfeld, S. L., Reardon, T. C., \& Tonge, B. J. (2014). Adult Outcomes in Autism: Community Inclusion and Living Skills. Journal of Autism and Developmental Disorders, 44(12), 3006-3015. doi:10.1007/s10803-014-2159-x

Haertl, K., Callahan, D., Markovics, J., \& Sheppard, S. S. (2013). Perspectives of Adults Living With Autism Spectrum Disorder: Psychosocial and Occupational Implications. Occupational Therapy in Mental Health, 29(1), 27-41. doi:10.1080/0164212X.2012.760303

Hagberg, B., Billstedt, E., Nyden, A., \& Gillberg, C. (2015). Asperger syndrome and nonverbal learning difficulties in adult males: self- and parent-reported autism, attention and executive problems. European Child \& Adolescent Psychiatry, 24(8), 969-977. doi:10.1007/s00787-014-0646-4

Hagberg, B., Nyden, A., Cederlund, M., \& Gillberg, C. (2013). Asperger syndrome and "non-verbal learning problems" in a longitudinal perspective: Neuropsychological and social adaptive outcome in early adult life. Psychiatry Research, 210(2), 553-558. doi:10.1016/j.psychres.2013.06.006

Happé, F., Booth, R., Charlton, R., \& Hughes, C. (2006). Executive function deficits in autism spectrum disorders and attention-deficit/hyperactivity disorder: examining profiles across domains and ages. Brain and Cognition, 61(1), 25-39. 
Running Head: PSYCHOSOCIAL OUTCOMES OF ADULTS WITH ASD

Hare, D. J., Gracey, C., \& Wood, C. (2015). Anxiety in high-functioning autism: A pilot study of experience sampling using a mobile platform. Autism, 1362361315604817.

Hare, D. J., Wood, C., Wastell, S., \& Skirrow, P. (2014). Anxiety in Asperger's syndrome: Assessment in real time. Autism, 19(5), 542-552. doi:10.1177/1362361314531340

Hill, E. L. (2004). Executive dysfunction in autism. Trends in Cognitive Sciences, 8(1), 26-32.

Hill, E. L., Berthoz, S., \& Frith, U. (2004). Brief report: cognitive processing of own emotions in individuals with autistic spectrum disorder and in their relatives. Journal of Autism and Developmental Disorders, 34(2), 229-235. doi:10.1023/B:JADD.0000022613.41399.14

Hill, E. L., \& Bird, C. M. (2006). Executive processes in Asperger syndrome: Patterns of performance in a multiple case series. Neuropsycholgia, 44, 2822-2835. doi:10.1016/j.neuropsychologia.2006.06.007

Hirvikoski, T., \& Blomqvist, M. (2015). High self-perceived stress and poor coping in intellectually able adults with autism spectrum disorder. Autism, 19(6), 752-757.

Hofvander, B., Delorme, R., Chaste, P., Nyden, A., Wentz, E., Stahlberg, O., . . . Leboyer, M. (2009). Psychiatric and psychosocial problems in adults with normal-intelligence autism spectrum disorders. BMC Psychiatry, 9. doi:10.1186/1471-244x-9-35

Howlin, P. (2000). Outcome in adult life for more able individuals with autism or Asperger syndrome. Autism, 4(1), 63-83. doi:10.1177/1362361300004001005

Howlin, P. (2003). Outcome in high-functioning adults with autism with and without early language delays: Implications for the differentiation between autism and Asperger syndrome. Journal of Autism and Developmental Disorders, 33(1), 313. doi:10.1023/A:1022270118899

Howlin, P., \& Moss, P. (2012). Adults With Autism Spectrum Disorders. Canadian Journal of Psychiatry-Revue Canadienne De Psychiatrie, 57(5), 275-283.

Jansch, C., \& Hare, D. J. (2014). An Investigation of the "Jumping to Conclusions" Data-Gathering Bias and Paranoid Thoughts in Asperger Syndrome. Journal of Autism and Developmental Disorders, 44(1), 111-119. doi:10.1007/s10803-013$1855-2$ 
Running Head: PSYCHOSOCIAL OUTCOMES OF ADULTS WITH ASD

Jantz, K. M. (2011). Support Groups for Adults With Asperger Syndrome. Focus on Autism and Other Developmental Disabilities, 26(2), 119-128. doi:10.1177/1088357611406903

Khanna, R., Jariwala-Parikh, K., West-Strum, D., \& Mahabaleshwarkar, R. (2014). Health-related quality of life and its determinants among adults with autism. Research in Autism Spectrum Disorders, 8(3), 157-167. doi:10.1016/j.rasd.2013.11.003

Kleinhans, N., Akshoomoff, N., \& Delis, D. (2005). Executive functions in autism and Asperger's Disorder: Flexibility, fluency, and inhibition. Developmental Neuropsychology, 27, 379-401. doi:10.1207/s15326942dn2703_5

Lauwerier, E., Crombez, G., Van Damme, S., Goubert, L., Vogelaers, D., \& Evers, A. W. M. (2010). The construct validity of the Illness Cognition Questionnaire: The robustness of the three-factor structure across patients with chronic pain and chronic fatigue. International Journal of Behavioral Medicine, 17(2), 90-96. doi:10.1007/s12529-009-9059-Z

Lazarus, R. S., \& Folkman, S. (1984). Stress, Coping, and Adaptation. New York: Springer.

Levy, A., \& Perry, A. (2011). Outcomes in adolescents and adults with autism: A review of the literature. Research in Autism Spectrum Disorders, 5(4), 12711282. doi:10.1016/j.rasd.2011.01.023

Lopez, B. R., Lincoln, A. J., Ozonoff, S., \& Lai, Z. (2005). Examining the relationship between executive functions and restricted, repetitive symptoms of autistic disorder. Journal of Autism and Developmental Disorders, 35(4), 445-460.

Lord, C. (1994). Autism diagnostic interview-revised: A revised version of a diagnostic interview for caregivers of individuals with possible pervasive developmental disorders. Journal of Autism and Developmental Disorders, 24(5), 659-685. doi:10.1007/BF02172145

Maddox, B. B., \& White, S. W. (2015). Comorbid social anxiety disorder in adults with autism spectrum disorder. Journal of Autism and Developmental Disorders, No Pagination Specified.

Magiati, I., Tay, X. W., \& Howlin, P. (2012). Early comprehensive behaviorally based interventions for children with autism spectrum disorders: a summary of findings from recent reviews and meta-analyses. Neuropsychiatry, 2(6), 543570. 
Running Head: PSYCHOSOCIAL OUTCOMES OF ADULTS WITH ASD

Magiati, I., Tay, X. W., \& Howlin, P. (2014). Cognitive, language, social and behavioural outcomes in adults with autism spectrum disorders: A systematic review of longitudinal follow-up studies in adulthood. Clinical Psychology Review, 34(1), 73-86. doi:10.1016/j.cpr.2013.11.002

Mayer, J. D., Salovey, P., Caruso, D. R., \& Sitarenios, G. (2001). Emotional intelligence as a standard intelligence.

McCracken, L. M. (2005). A prospective study of acceptance of pain and patient functioning with chronic pain. Pain, 118(1-2), 164-169. doi:10.1016/j.pain.2005.08.015

McDonald, S. (2013). Impairments in social cognition following severe traumatic brain injury. Journal of the International Neuropsychological Society, 19(03), 231246.

Merkler, E. E. (2007). The experience of isolation and loneliness in young adults with high-functioning autism. Dissertation Abstracts International: Section B: The Sciences and Engineering, 68(3-B), 1936. Retrieved from http://libraryproxy.griffith.edu.au/login?url=http://ovidsp.ovid.com/ovidweb.cgi $? \mathrm{~T}=\mathrm{JS} \& \mathrm{CSC}=\mathrm{Y} \& \mathrm{NEWS}=\mathrm{N} \& \mathrm{PAGE}=$ fulltext $\& \mathrm{D}=\mathrm{psyc} 5 \& \mathrm{AN}=2007-99018-265$

Meyer, B. (2001). Coping with severe mental illness: Relations of the Brief COPE with symptoms, functioning, and well-being. Journal of Psychopathology and Behavioral Assessment, 23(4), 265-277.

Moher, D., Liberati, A., Tetzlaff, J., \& Altman, D. G. (2009). Preferred reporting items for systematic reviews and meta-analyses: the PRISMA statement. Annals of internal medicine, 151(4), 264-269.

Montgomery, J. M., Stoesz, B. M., \& McCrimmon, A. W. (2013). Emotional Intelligence, Theory of Mind, and Executive Functions as Predictors of Social Outcomes in Young Adults With Asperger Syndrome. Focus on Autism and Other Developmental Disabilities, 28(1), 4-13. doi:10.1177/1088357612461525

Muller, E., Schuler, A., \& Yates, G. B. (2008). Social challenges and supports from the perspective of individuals with Asperger syndrome and other autism spectrum disabilities. Autism, 12(2), 173-190. doi:10.1177/1362361307086664

Nordin, V., \& Gillberg, C. (1998). The long-lerm course of autistic disorders: Update on follow-up studies. Acta Psychiatrica Scandinavica, 97(2), 99-108. doi:10.1111/j.1600-0447.1998.tb09970.x 
Running Head: PSYCHOSOCIAL OUTCOMES OF ADULTS WITH ASD

Ownsworth, T., \& McKenna, K. (2004). Investigation of factors related to employment outcome following traumatic brain injury: a critical review and conceptual model. Disability \& Rehabilitation, 26(13), 765-783.

Payne, T. J., Andrew, M., Butler, K. R., Wyatt, S. B., Dubbert, P. M., \& Mosley, T. M. (2012). Psychometric evaluation of the Interpersonal Support Evaluation ListShort Form in the ARIC study cohort. SAGE Open, 1-8. doi:10.1177/2158244012461923

Pellicano, E. (2007). Links between theory of mind and executive function in young children with autism: clues to developmental primacy. Developmental psychology, 43(4), 974.

Pennington, B. F., \& Ozonoff, S. (1996). Executive functions and developmental psychopathology. Journal of Child Psychology and Psychiatry, 37(1), 51-87. doi:10.1111/j.1469-7610.1996.tb01380.x

Pottie, C. G., \& Ingram, K. M. (2008). Daily stress, coping, and well-being in parents of children with autism: A multilevel modeling approach. American Psychological Association, 22(6), 855-864. doi:10.1037/a0013604

Rajendran, G., \& Mitchell, P. (2007). Cognitive theories of autism. Developmental Review, 27, 224-260. doi:10.1016/j.d.r.2007.02.001

Rajendran, G., Mitchell, P., \& Rickards, H. (2005). How do individuals with Asperger syndrome respond to nonliteral language and inappropriate requests in computer-mediated communication? Journal of Autism and Developmental Disorders, 35(4), 429-443. doi:10.1007/s10803-005-5033-Z

Reiersen, A., \& Todd, R. (2008). Co-occurrence of ADHD and autism spectrum disorders: phenomenology and treatment.

Renty, J., \& Roeyers, H. (2006). Quality of life in high-functioning adults with autism spectrum disorder: The predictive value of disability and support characteristics. Autism, 10(5), 511-524. doi:10.1177/1362361306066604

Renty, J., \& Roeyers, H. (2007). Individual and Marital Adaptation in Men with Autism Spectrum Disorder and their Spouses: The Role of Social Support and Coping Strategies. Journal of Autism and Developmental Disorders, 37(7), 1247-1255. doi:10.1007/s10803-006-0268-X

Rinaldi, R., Jacquet, E., \& Lefebvre, L. (2015). Neurocognitive characteristics of psychotic symptoms in young adults with high functioning autism. Research in Autism Spectrum Disorders, 17, 135-141. doi:10.1016/j.rasd.2015.06.008 
Running Head: PSYCHOSOCIAL OUTCOMES OF ADULTS WITH ASD

Roekel, G. H. v., Didden, H. C. M., \& Scholte, R. H. J. (2010). Bullying Among Adolescents With Autism Spectrum Disorders: Prevalence and Perception. Journal of Autism and Developmental Disorders, 40(1), 63-73. doi:10.1007/s10803-009-0832-2

Rosengren, A., Orth-Gomer, K., Wedel, H., \& Wilhelmsen, L. (1993). Stressful life events, social support, and mortality in men born in 1933. British Medical Journal, 307(6912), 1102-1105. doi:10.1136/bmj.307.6912.1102

Samson, A. C., Huber, O., \& Gross, J. J. (2012). Emotion regulation in Asperger's syndrome and high functioning autism. Emotion, 12(4), 659-665. doi:10.1037/a0027975

Schmidt, L., Kirchner, J., Strunz, S., Brozus, J., Ritter, K., Roepke, S., \& Dziobek, I. (2015). Psychosocial functioning and life satisfaction in adults with autism spectrum disorder without intellectual impairment. Journal of Clinical Psychology, 71(12), 1259-1268.

Shtayermman, O. (2007). Peer Victimization in Adolescents and Young Adults Diagnosed with Asperger's Syndrome: A Link to Depressive Symptomatology, Anxiety Symptomatology and Suicidal Ideation. Issues in Comprehensive Pediatric Nursing, 30(3), 87-107. doi:10.1080/01460860701525089

Silva, B., Filipini, R., de Mello Monteiro, C. B., Valenti, V. E., de Carvalho, S. M., Wajnsztejn, R., . . . de Abreu, L. C. (2013). The biopsychosocial processes in autism spectrum disorder. International Archives of Medicine, 6(1), 22-27. doi:10.1186/1755-7682-6-22

Smith, R. S., \& Sharp, J. (2013). Fascination and Isolation: A Grounded Theory Exploration of Unusual Sensory Experiences in Adults with Asperger Syndrome. Journal of Autism and Developmental Disorders, 43(4), 891-910. doi:10.1007/s10803-012-1633-6

South, M., Stephenson, K. G., Nielson, C. A., Maisel, M., Top, D. N., \& Kirwan, C. B. (2015). Overactive pattern separation memory associated with negative emotionality in adults diagnosed with autism spectrum disorder. Journal of Autism and Developmental Disorders, 45(11), 3458-3467. doi:10.1007/s10803015-2547-x

Sparrow, S., Balla, D., \& Cicchetti, D. (1984). Vineland Adaptive Behavior Scales. Circle Pines, MN: American Guidance Service. 
Running Head: PSYCHOSOCIAL OUTCOMES OF ADULTS WITH ASD

Steptoe, A. (2000). Psychosocial factors in the development of hypertension. Annals of Medicine, 32, 371-375. doi:10.3109/07853890008995940

Szatmari, P., Bartolucci, G., Bremner, R., Bond, S., \& Rich, S. (1989). A follow-up study of high-functioning Autistic children. Journal of Autism and Developmental Disorders, 19(2), 213-225. doi:10.1007/BF02211842

Tani, M., Kanai, C., Ota, H., Yamada, T., Watanabe, H., Yokoi, H., . . Iwanami, A. (2012). Mental and behavioral symptoms of person's with Asperger's syndrome: Relationships with social isolation and handicaps. Research in Autism Spectrum Disorders, 6(2), 907-912. doi:10.1016/j.rasd.2011.12.004

Taylor, J. L., Henninger, N. A., \& Mailick, M. R. (2015). Longitudinal patterns of employment and postsecondary education for adults with autism and averagerange IQ. Autism, 19(7), 785-793. doi:10.1177/1362361315585643

Tobin, M. C., Drager, K. D. R., \& Richardson, L. F. (2014). A systematic review of social participation for adults with autism spectrum disorders: Support, social functioning, and quality of life. Research in Autism Spectrum Disorders, 8(3), 214-229. doi:10.1016/j.rasd.2013.12.002

Townson, L., Macauley, S., Harkness, E., Docherty, A., Dias, J., Eardley, M., \& Chapman, R. (2007). Research project on advocacy and autism. Disability \& Society, 22(5), 523-536. doi:10.1080/09687590701427669

Turner, M. A. (1999). Generating novel ideas: Fluency performance in high-functioning and learning disabled individuals with autism. Journal of Child Psychology and Psychiatry, 40(2), 189-201. doi:10.1111/1469-7610.00432

van Heijst, B. F., \& Geurts, H. M. (2014). Quality of life in autism across the lifespan: A meta-analysis. Autism, 1362361313517053.

Vickerstaff, S., Heriot, S., Wong, M., Lopes, A., \& Dossetor, D. (2007). Intellectual ability, self-perceived social competence, and depressive symptomatology in children with high-functioning autistic spectrum disorders. Journal of Autism and Developmental Disorders, 37(9), 1647-1664. doi:10.1007/s10803-0060292-x

Wallace, G. L., Kenworthy, L., Pugliese, C. E., Popal, H. S., White, E. I., Brodsky, E., \& Martin, A. (2015). Real-World Executive Functions in Adults with Autism Spectrum Disorder: Profiles of Impairment and Associations with Adaptive Functioning and Co-morbid Anxiety and Depression. Journal of Autism and Developmental Disorders, 1-13. 
Running Head: PSYCHOSOCIAL OUTCOMES OF ADULTS WITH ASD

Williamson, S., Craig, J., \& Slinger, R. (2008). Exploring the relationship between measures of self-esteem and psychological adjustment among adolescents with Asperger Syndrome. Autism, 12(4), 391-402.

World Health Organization. (1993). International classification of diseases: Tenth revision. Mental and behavioural disorders (including disorders of psychological development). Diagnostic criteria for research. Geneva: Author. 


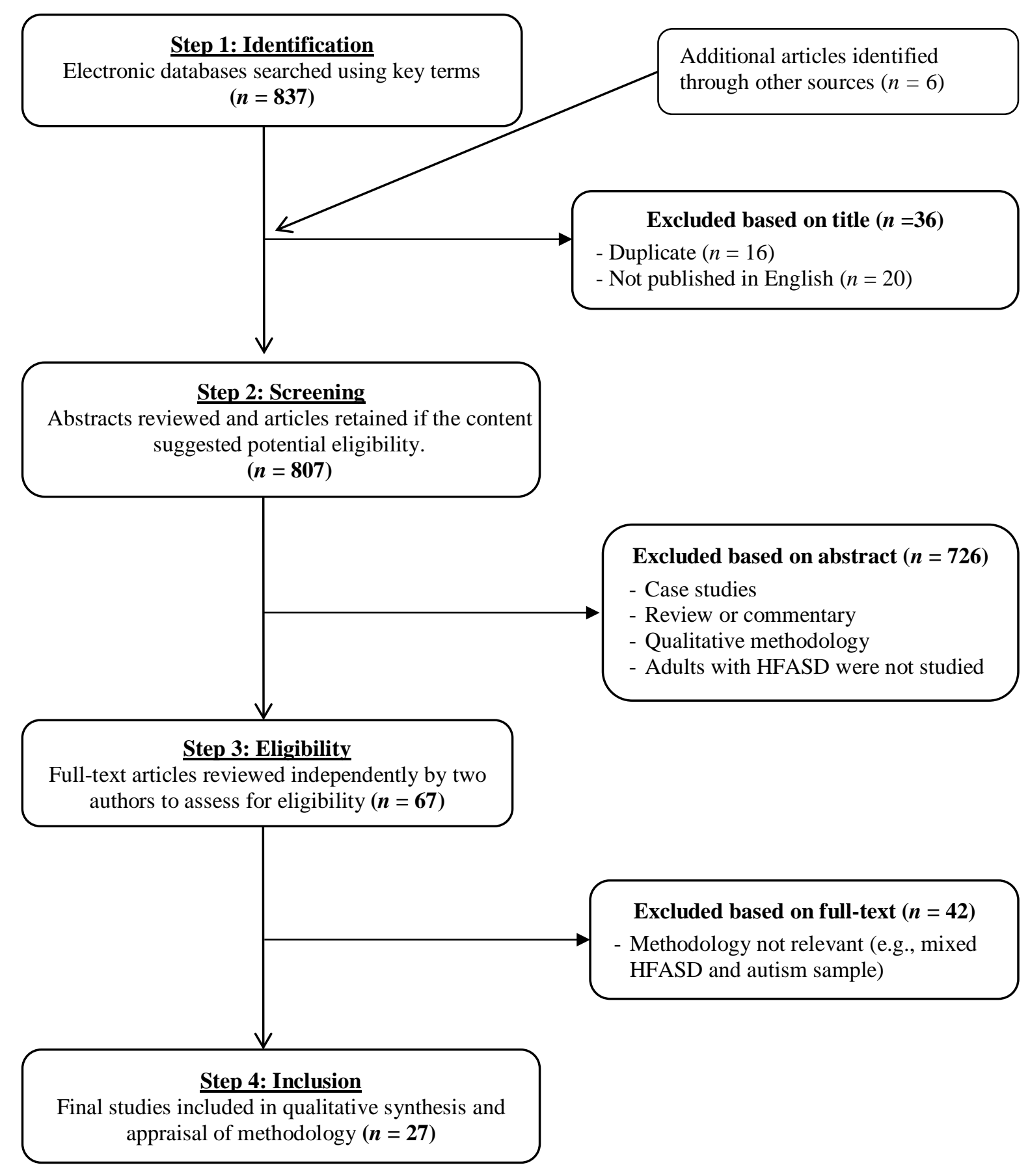

Figure 1. Flow diagram of literature search and study selection 
Table 1

Summary of Studies Investigating Factors Related to Psychosocial Outcomes in Adults with HFASD

\begin{tabular}{|c|c|c|c|c|c|}
\hline Authors & $\begin{array}{l}\text { Design and Sample } \\
\text { (Mean Age) }\end{array}$ & Correlates/Predictors & Psychosocial Outcomes & $\begin{array}{l}\text { Quality of } \\
\text { Methodology }\end{array}$ & Significant Findings \\
\hline $\begin{array}{l}\text { Abell and Hare } \\
(2005)\end{array}$ & $\begin{array}{l}\text { Cross-sectional } \\
n=46 \text { (32.5 years) }\end{array}$ & $\begin{array}{l}\text { Age, self-consciousness, } \\
\text { executive functioning, } \\
\text { delusional beliefs, non-verbal } \\
\& \text { verbal IQ, FSIQ, theory of } \\
\text { mind (ToM), autobiographical } \\
\text { memory }\end{array}$ & $\begin{array}{l}\text { Anxiety and depression } \\
\text { (HADS) }\end{array}$ & 1 & $\begin{array}{l}\text { Older age, greater delusional beliefs and self- } \\
\text { consciousness correlated with anxiety. Older } \\
\text { age was also related to increased depression }\end{array}$ \\
\hline $\begin{array}{l}\text { Berger, Aerts, van } \\
\text { Spaendonck, Cools, } \\
\text { and Teunisse (2003) }\end{array}$ & $\begin{array}{l}\text { Prospective } \\
n=30 \text { ( } 19.3 \text { years }), 3 \\
\text { year follow-up interval }\end{array}$ & $\begin{array}{l}\text { Time 1: central coherence, } \\
\text { cognitive shifting; Time } 1 \& \\
2 \text { : Social functioning } \\
\text { (symptom severity, social } \\
\text { understanding \& competence) }\end{array}$ & $\begin{array}{l}\text { Improvement in social } \\
\text { competence (VABS) }\end{array}$ & 2 & $\begin{array}{l}\text { Cognitive shifting was identified as an early } \\
\text { prognostic marker of social competence }\end{array}$ \\
\hline $\begin{array}{l}\text { Bishop-Fitzpatrick, } \\
\text { Mazefsky, Minshew } \\
\text { and Eack (2015) }\end{array}$ & $\begin{array}{l}\text { Cross-sectional } \\
n=38 \text { (23.1 years) }\end{array}$ & Age and education & $\begin{array}{l}\text { Stress (Brief Psychiatric } \\
\text { Rating Scale); Social } \\
\text { Functioning (Global } \\
\text { Assessment Scale; } \\
\text { Social Adjustment } \\
\text { Scale-II) }\end{array}$ & 3 & $\begin{array}{l}\text { Older age, but not education, was related to } \\
\text { poorer social functioning (note: associations } \\
\text { with stress were not examined) }\end{array}$ \\
\hline Farley et al. (2009) & $\begin{array}{l}\text { Prospective } \\
n=41 \text { ( } 32.5 \text { years }) \\
\text { mean time interval to } \\
\text { follow-up } 24.42 \text { years }\end{array}$ & $\begin{array}{l}\text { Social support (vocational } \\
\text { rehabilitation, government } \\
\text { disabilities support), FSIQ }\end{array}$ & $\begin{array}{l}\text { Social functioning rating } \\
\text { (very good-very poor) } \\
\text { and adaptive behaviour } \\
\text { (VABS) }\end{array}$ & 3 & $\begin{array}{l}\text { Childhood FSIQ predicted VABS scores in } \\
\text { adulthood. Greater gains in intellectual } \\
\text { functioning(IQ) were associated with better } \\
\text { social and adaptive outcomes }\end{array}$ \\
\hline $\begin{array}{l}\text { Gillberg, Helles, } \\
\text { Billstedt, and } \\
\text { Gillberg (2015) }\end{array}$ & $\begin{array}{l}\text { Prospective } \\
n=50 \text { ( } 30 \text { years }) \\
\text { mean time interval to } \\
\text { follow-up } 9.4 \text { years }\end{array}$ & FSIQ, VIQ, PIQ & $\begin{array}{l}\text { Depression (BDI), } \\
\text { psychiatric disorders } \\
\text { (Mini Neuropsychiatric } \\
\text { Interview), GAF, ADHD } \\
\text { (Adult ADHD Self- } \\
\text { Report Scale ; SNAP- }\end{array}$ & 4 & $\begin{array}{l}\text { Lower current FSIQ and non-verbal IQ was } \\
\text { associated with ADHD symptoms. }\end{array}$ \\
\hline
\end{tabular}


Gotham, Unruh, and Cross-sectional

Lord (2014);

Gotham, Bishop,

Brunwasser, and

Lord (2014)

\section{Hagberg, Nyden,}

Cederlund, and

Gillberg (2013);

Hagberg, Billstedt,

Nyden, and Gillberg

(2015)

Hare, Wood, $n=50$ (20.7 years)

Wastell, and Skirrow (2014);

$\begin{array}{ll}\begin{array}{l}\text { Hill, Berthoz, and } \\ \text { Frith (2004) }\end{array} & \begin{array}{l}\text { Cross-sectional } \\ n=27 \text { (35.1 years) }\end{array} \\ \begin{array}{l}\text { Hirvikoski and } \\ \text { Blomqvist (2015) }\end{array} & \begin{array}{l}\text { Cross-sectional } \\ n=25 \text { (34.1 years) }\end{array} \\ \text { Howlin (2003) } & \begin{array}{l}\text { Cross-sectional } \\ n=76 \text { (26.1 years) }\end{array} \\ & \\ \text { Jansch and Hare } & \text { Cross-sectional } \\ \text { (2014) } & n=30 \text { (32.23 years) }\end{array}$

Age, gender, FSIQ, ASD

related impairments,

Depression

Questionnaire), Anxiety

(Spence Children's

Anxiety Scale-Parent),

adaptive behaviour

(VABS)

Childhood ASD diagnosis and Social adaptive interview, cognitive behaviour (VABS);

assessment (verbal and non- $\quad$ GAF; ADHD (SNAP-

verbal IQ, executive function, IV)

central coherence, memory)

Thinking characteristics (e.g., Anxiety and Depression

self-focus, confusion, worries (HADS)

about everyday events and

rumination)

Emotion processing on the Toronto Alexithymia Scale

ASD symptoms

Autism and Asperger

diagnoses, non-verbal IQ,

comprehension, vocabulary,

parent interview

Depression (BDI)

ASD symptoms, mentalisation (Reading the Mind in the Eyes Test), data gathering bias (Beads Task)

The Perceived Stress Scale (PSS)

Social outcomes (Autism Diagnostic Interview) and social functioning

Depression (PHQ), generalised anxiety (Generalised Anxiety
(BDI-II; Self-Report

Greater ASD impairments and rumination and lower levels of perceived social-support, motivation and participation were related to increased depression. Rumination moderated the relationship between ASD symptoms and depression.

Adults with lifelong non-verbal disability had worse GAF than those with childhood only non-verbal disability. Those with lifelong non-verbal disability had worse social adaptive outcomes than those with no history of non-verbal disability; Poorer childhood non-verbal IQ was associated with ADHD symptoms in adulthood

1 Self-focus, worries and longer periods of rumination were positively associated with anxiety

Emotion processing was not significantly related to depression Disorder-7), selfconsciousness (Self
Greater ASD symptoms were associated with higher perceived stress

2 The Asperger subgroup achieved higher education attainment than the autism subgroup.
Greater ASD symptoms were associated with depression and anxiety 


\begin{tabular}{|c|c|c|c|c|c|}
\hline & & & $\begin{array}{l}\text { Consciousness Scale), } \\
\text { paranoid thoughts } \\
\text { (Paranoid Thought } \\
\text { Scales) }\end{array}$ & & \\
\hline Jantz (2011) & $\begin{array}{l}\text { Cross-sectional } \\
n=35 \text { ( } 45 \text { years) }\end{array}$ & Age, gender, ASD symptoms & $\begin{array}{l}\text { Loneliness (UCLA } \\
\text { Loneliness Scale) }\end{array}$ & 1 & $\begin{array}{l}\text { Greater ASD symptoms were related to } \\
\text { increased loneliness }\end{array}$ \\
\hline $\begin{array}{l}\text { Khanna, Jariwala- } \\
\text { Parikh, West-Strum, } \\
\text { and } \\
\text { Mahabaleshwarkar } \\
\text { (2014) }\end{array}$ & $\begin{array}{l}\text { Cross-sectional } \\
n=291 \text { (30.7 years) }\end{array}$ & $\begin{array}{l}\text { Age, gender, ASD severity, } \\
\text { perceived social support, } \\
\text { coping }\end{array}$ & $\begin{array}{l}\text { Health-related QoL } \\
\text { (HRQoL): Physical and } \\
\text { mental (The Medical } \\
\text { Outcomes Study Short- } \\
\text { Form Health Survey } \\
\text { version 2) }\end{array}$ & 2 & $\begin{array}{l}\text { Poorer perceptions of social support from } \\
\text { friends, ASD severity and maladaptive coping } \\
\text { strategies were related to poorer physical and } \\
\text { mental HRQoL. }\end{array}$ \\
\hline $\begin{array}{l}\text { Maddox and White } \\
\text { (2015) }\end{array}$ & $\begin{array}{l}\text { Cross-sectional } \\
n=28 \text { ( } 32.23 \text { years })\end{array}$ & $\begin{array}{l}\text { ASD symptoms (Social } \\
\text { Responsiveness Scale-II) }\end{array}$ & $\begin{array}{l}\text { Social Anxiety Disorder } \\
\text { Symptoms (Anxiety } \\
\text { Disorders Interview } \\
\text { Schedule-DSM-IV } \\
\text { [ADIS-IV]) }\end{array}$ & 2 & $\begin{array}{l}\text { Greater ASD related social impairments were } \\
\text { associated with social anxiety disorder } \\
\text { symptoms. }\end{array}$ \\
\hline $\begin{array}{l}\text { Montgomery, Stoesz, } \\
\text { and McCrimmon } \\
\text { (2013) }\end{array}$ & $\begin{array}{l}\text { Cross-sectional } \\
n=25 \text { (18.2 years) }\end{array}$ & $\begin{array}{l}\text { HFASD symptoms, Verbal } \\
\text { IQ, ToM, executive functions, } \\
\text { emotional intelligence }\end{array}$ & $\begin{array}{l}\text { Interpersonal relations } \\
\text { and social stress } \\
\text { (Behaviour Assessment } \\
\text { System for Children-2) }\end{array}$ & 2 & $\begin{array}{l}\text { Greater emotional intelligence was related to } \\
\text { better interpersonal relations. Those with } \\
\text { greater emotional intelligence and ToM had } \\
\text { lower social stress }\end{array}$ \\
\hline $\begin{array}{l}\text { Renty and Roeyers } \\
\text { (2006) }\end{array}$ & $\begin{array}{l}\text { Cross-sectional } \\
n=58 \text { (28.3 years) }\end{array}$ & $\begin{array}{l}\text { Age, gender, ASD symptoms, } \\
\text { FSIQ (ASD symptoms + FSIQ } \\
\text { = disability characteristics), } \\
\text { support characteristics } \\
\text { (perceived, received) }\end{array}$ & $\begin{array}{l}\text { Quality of Life } \\
\text { Questionnaire }\end{array}$ & 2 & $\begin{array}{l}\text { Perceived support was significantly related to } \\
\text { QoL; perceived and received support } \\
\text { characteristics were better predictors of QoL } \\
\text { than disability characteristics. }\end{array}$ \\
\hline $\begin{array}{l}\text { Renty and Roeyers } \\
\text { (2007) }\end{array}$ & $\begin{array}{l}\text { Cross-sectional } \\
n=21 \text { (43.5 years) }\end{array}$ & $\begin{array}{l}\text { Males with ASD, ASD } \\
\text { symptoms, informal social } \\
\text { support - spouse and family, } \\
\text { received support - spouse and } \\
\text { family, formal support, coping } \\
\text { strategies }\end{array}$ & $\begin{array}{l}\text { Psychological distress - } \\
\text { individual satisfaction } \\
\text { (The Symptom } \\
\text { Checklist-90), marital } \\
\text { satisfaction (Dyadic } \\
\text { Adjustment Scale) }\end{array}$ & 1 & $\begin{array}{l}\text { Informal support was related to psychological } \\
\text { functioning and marital adaptation for men } \\
\text { with ASD. Severity of ASD symptoms in men } \\
\text { was negatively associated with spouse marital } \\
\text { satisfaction. Coping was not related to } \\
\text { outcomes. }\end{array}$ \\
\hline Rinaldi, Jacquet, and & Cross-sectional & Executive function & Development of & 1 & Interference control distinguished between \\
\hline
\end{tabular}




\begin{tabular}{|c|c|c|c|}
\hline Lefebvre (2015) & $n=17(17.88$ years $)$ & (interference control) & psychotic symptoms \\
\hline Schmidt et al. (2015) & $\begin{array}{l}\text { Cross-sectional } \\
n=43 \text { (31 years) }\end{array}$ & $\begin{array}{l}\text { Psychological resources and } \\
\text { general functioning } \\
\text { (WHODAS) }\end{array}$ & $\begin{array}{l}\text { Life satisfaction } \\
\text { (German Quality of Life } \\
\text { Questionnaire) }\end{array}$ \\
\hline Shtayermman (2007) & $\begin{array}{l}\text { Cross-sectional } \\
n=10(19.7 \text { years })\end{array}$ & $\begin{array}{l}\text { HFASD symptoms, peer } \\
\text { victimisation, level of stigma }\end{array}$ & $\begin{array}{l}\text { Anxiety, depression } \\
\text { (PHQ), suicidal ideation } \\
\text { (Suicidal Ideation } \\
\text { Questionnaire) }\end{array}$ \\
\hline South et al. (2015) & $\begin{array}{l}\text { Cross-sectional } \\
n=24 \text { (22.51 years) }\end{array}$ & $\begin{array}{l}\text { Pattern separation memory } \\
\text { task }\end{array}$ & $\begin{array}{l}\text { State-Trait anxiety scale; } \\
\text { Behavioural inhibition } \\
\text { and approach strategies } \\
\text { (Behavioural Inhibition } \\
\text { and Activation Scales) }\end{array}$ \\
\hline $\begin{array}{l}\text { Szatmari, Bartolucci, } \\
\text { Bremner, Bond, and } \\
\text { Rich (1989) }\end{array}$ & $\begin{array}{l}\text { Retrospective } \\
n=16 \\
\text { ( } 26.0 \text { years), mean time } \\
\text { interval to follow- } \\
\text { up11-27 years }\end{array}$ & $\begin{array}{l}\text { Early ASD symptoms, current } \\
\text { FSIQ, visuo-motor skills, } \\
\text { facial recognition, receptive } \\
\text { language, non-verbal problem } \\
\text { solving (cognitive shifting) } \\
\text { skills, visual motor integration }\end{array}$ & $\begin{array}{l}\text { Social adaptive } \\
\text { functioning (VABS) }\end{array}$ \\
\hline Tani et al. (2012) & $\begin{array}{l}\text { Cross-sectional } \\
n=99 \text { (30.7 years) }\end{array}$ & $\begin{array}{l}\text { ASD symptoms, } \\
\text { developmental and social } \\
\text { history (structured interview } \\
\text { with informant), FSIQ }\end{array}$ & $\begin{array}{l}\text { Psychological and } \\
\text { behavioural history } \\
\text { (mental health and } \\
\text { behavioural symptoms) }\end{array}$ \\
\hline $\begin{array}{l}\text { Taylor, Henninger, } \\
\text { and Mailick (2015) }\end{array}$ & $\begin{array}{l}\text { Prospective } \\
n=73 \text { ( } 23.83 \text { years) } \\
\text { over a } 12 \text { year follow- } \\
\text { up }\end{array}$ & $\begin{array}{l}\text { Gender, age, ASD symptoms, } \\
\text { maladaptive behaviours, daily } \\
\text { activities, parental education, } \\
\text { maternal social support, } \\
\text { depression, anxiety and } \\
\text { pessimism }\end{array}$ & $\begin{array}{l}\text { Employment and study } \\
\text { outcome (Vocational } \\
\text { Index) }\end{array}$ \\
\hline
\end{tabular}

those with ASD and those with ASD and psychotic symptoms.

3 Self-reported participation in society predicted improved life satisfaction.

1 Severity of ASD symptoms were negatively correlated with level of suicidal ideation

Poorer pattern separation memory was associated with greater state anxiety and behavioural approach strategies.

Current FSIQ and cognitive shifting correlated with social adaptive functioning, whereas early ASD symptoms were weakly associated with these outcomes

2 Adults with poor lifestyle habits had greater depression; Circumscribed interests were related to anxiety; Those bullied at school had less stable emotions and mood swings Males were more likely to be employed or studying than females after high school; Those with fathers with higher education attainment were more likely to obtain and maintain employment or tertiary education 
Wallace et al. (2015) Cross-sectional

$n=35$ (21.55 years)
Age, FSIQ, Executive

functioning (behaviour

Adaptive functioning

(Adaptive Behaviour

regulation and metacognition) Assessment System-II)

anxiety, depression an

ADHD (Adult Behavior

CheckList)
2 Poorer planning was related to worse adaptive functioning and increased depression,

whereas poorer shifting was related to greater anxiety.

BDI-II = Beck Depression Inventory; GAF = Global Assessment of Functioning; HADS = Hospital Anxiety and Depression Scale; PHQ= Patient Health Questionnaire; SNAP-IV = Swanson, Nolan and Pelham Questionnaire; VABS = Vineland Adaptive Behavior Scale. 
Table 2

Ratings of Quality of Methodology of Included Studies

\begin{tabular}{|c|c|c|c|c|c|c|}
\hline Study & $\begin{array}{c}\text { Prospective/Retrospective } \\
\text { Design }\end{array}$ & $\begin{array}{c}\text { Sample } \\
\text { Characteristics }\end{array}$ & $\begin{array}{c}\text { Sample } \\
\text { representativeness }\end{array}$ & $\begin{array}{c}\text { Adequate } \\
\text { sample size }\end{array}$ & $\begin{array}{l}\text { Multivariate } \\
\text { Analysis }\end{array}$ & Total $(0-5)$ \\
\hline Abell and Hare (2005) & $x$ & $\checkmark$ & $x$ & $x$ & $x$ & 1 \\
\hline $\begin{array}{l}\text { Berger, Aerts, van } \\
\text { Spaendonck, Cools, and } \\
\text { Teunisse (2003) }\end{array}$ & $\checkmark$ & $\checkmark$ & $x$ & $x$ & $x$ & 2 \\
\hline $\begin{array}{l}\text { Bishop-Fitzpatrick, Mazefsky, } \\
\text { Minshew and Eack (2015) }\end{array}$ & $x$ & $\checkmark$ & $x$ & $\checkmark$ & $\checkmark$ & 3 \\
\hline $\begin{array}{l}\text { Byers, Nichols, Voyer, and } \\
\text { Reilly (2013) }\end{array}$ & $x$ & $\checkmark$ & $\checkmark$ & $\checkmark$ & $\checkmark$ & 4 \\
\hline Farley et al. (2009) & $\checkmark$ & $\checkmark$ & $\checkmark$ & $x$ & $x$ & 3 \\
\hline $\begin{array}{l}\text { Gillberg, Helles, Billstedt, } \\
\text { and Gillberg (2015) }\end{array}$ & $\checkmark$ & $\checkmark$ & $\checkmark$ & $\checkmark$ & $x$ & 4 \\
\hline $\begin{array}{l}\text { Gotham, Unruh, and Lord } \\
\text { (2014); Gotham, Bishop, } \\
\text { Brunwasser, and Lord (2014) }\end{array}$ & $x$ & $\checkmark$ & $x$ & $\checkmark$ & $x$ & 2 \\
\hline $\begin{array}{l}\text { Hagberg, Nyden, Cederlund, } \\
\text { and Gillberg (2013); Hagberg } \\
\text { et al. (2015) }\end{array}$ & $\checkmark$ & $\checkmark$ & $x$ & $\checkmark$ & $x$ & 3 \\
\hline $\begin{array}{l}\text { Hare, Wood, Wastell, and } \\
\text { Skirrow (2014); }\end{array}$ & $x$ & $\checkmark$ & $x$ & $x$ & $x$ & 1 \\
\hline $\begin{array}{l}\text { Hill, Berthoz, and Frith } \\
\text { (2004) }\end{array}$ & $x$ & $x$ & $x$ & $\checkmark$ & $\checkmark$ & 2 \\
\hline
\end{tabular}


Hirvikoski and Blomqvist

(2015)

Howlin (2003)

Jansch and Hare (2014)

Jantz (2011)

Khanna, Jariwala-Parikh,

West-Strum, and

Mahabaleshwarkar (2014)

Maddox and White (2015)

Montgomery, Stoesz, and

McCrimmon (2013)

Renty and Roeyers (2006)

Renty and Roeyers (2007)

Rinaldi, Jacquet, and

Lefebvre (2015)

Schmidt et al. (2015)

Shtayermman (2007)

South et al. (2015)

Szatmari, Bartolucci,

Bremner, Bond, and Rich

(1989) $x$

x

$x$

$x$

$x$

$x$

$x$

$x$

$x$

x $x$

$x$

$x$

$x$

$x$

$x$

$x$

$\checkmark$
2

1

2

2

2

2

1

1

3

x

$x$

2

$x$

x

3 
Tani et al. (2012)

Taylor, Henninger, and Mailick (2015)

Wallace et al. (2015) $\mathbf{x}$ $\checkmark$

x $x$

2 